\title{
Distinct association between aberrant methylation of Wnt inhibitors and genetic alterations in acute myeloid leukaemia
}

\author{
H-A Hou ${ }^{1,2,7}$, Y-Y Kuo ${ }^{3,7}$, C-Y Liu', MC Lee', J-L Tang', C-Y Chen', W-C Chou ${ }^{1,5}$, C-F Huang', F-Y Lee', \\ M-C Liu', M Yao' and H-F Tien ${ }^{*}, 1$
}

'Division of Hematology, Department of Internal Medicine, National Taiwan University, Taipei, Taiwan; ${ }^{2}$ Graduate Institute of Clinical Medicine, College of Medicine, National Taiwan University, Taipei, Taiwan; ${ }^{3}$ Graduate Institute of Oncology, National Taiwan University, Taipei, Taiwan; ${ }^{4}$ Biostatistics Consulting Laboratory, Department of Nursing, National Taipei College of Nursing, Taipei, Taiwan; ${ }^{5}$ Department of Laboratory Medicine, National Taiwan University, Taipei, Taiwan; ${ }^{6}$ Department of Pathology, National Taiwan University Hospital, National Taiwan University, Taipei, Taiwan

BACKGROUND: Aberrant activation of Wnt signalling through hypermethylation of Wnt inhibitor genes is involved in several human malignancies, including acute myeloid leukaemia (AML). It remains unclear whether hypermethylation of Wnt inhibitors is associated with molecular gene mutations in the development of AML.

METHODS: We investigated the association of the promoter hypermethylation of six Wnt inhibitors (Wif-1, SFRPI, SFRR2, SFRP4, SFRP5, and DKKI) with gene aberrations in the leukaemogenesis of $269 \mathrm{AML}$ patients.

RESULTS: In total, 166 patients (61.7\%) had hypermethylation of at least one Wnt inhibitor. The majority (68.5\%) of patients with Wnt inhibitor hypermethylation had concurrent Class II gene mutations that affect transcription factors or cofactors. There was a close association of Wif-I hypermethylation with $\mathrm{t}(15 ; 17)(P=0.0005)$ and $C E B P A$ mutation $(P<0.000 \mid)$, DKKI hypermethylation with $\mathrm{t}(8 ; 2 \mathrm{I})(P<0.000 \mathrm{I})$ and ASXLI mutation $(P=0.0078)$, SFRP-I hypermethylation with $\mathrm{t}(8 ; 2 \mathrm{I})(P<0.000 \mathrm{I})$, SFRP-2 hypermethylation with AMLI/RUNXI mutation $(P=0.0012)$, and SFRP-5 hypermethylation with MLL/PTD $(P=0.0505)$. On the other side, hypermethylation of Wnt inhibitors was always negatively associated with NPM / mutation and FLT3/ITD.

CONCLUSION: There was distinct association between hypermethylation of individual Wnt inhibitors and specific gene aberrations, especially Class II mutations. The Wnt inhibitor hypermethylation might interact with genetic alterations in the leukaemogenesis. British Journal of Cancer (201 I) 105, 1927-1933. doi:I0.1038/bjc.201 I.47I www.bjcancer.com

Published online 17 November 2011

(c) 201I Cancer Research UK

Keywords: Wnt pathway inhibitors; methylation; genetic alteration; acute myeloid leukaemia

Acute myeloid leukaemia (AML) is a heterogeneous group of haematological malignancies with great variability in the pathogenesis and clinical course. A two-hit model proposes that the development of AML requires cooperation between at least two classes of gene mutations; Class I mutations, such as FLT3, RAS, JAK2, PTPN11, and KIT mutations activate genes in the kinase signalling pathways conferring proliferation and/or survival advantage to haematopoietic cells and Class II mutations, such as RUNX1/ RUNX1T1, PML/RAR $\alpha, C B F B / M Y H 11, M L L / P T D, A M L 1 / R U N X 1$, and $C E B P A$ mutations, affect transcription factors impairing haematopoietic differentiation (Gilliland, 2002; McCormack et al, 2008; Renneville et al, 2008). Recently, inappropriate gene silencing through epigenetic modification, such as aberrant methylation in the promoter areas of suppressor genes, was also found to affect the development and progression of malignancies (Jones and Baylin, 2002). A link between genetic and epigenetic changes has been well demonstrated in colorectal cancer (Herman et al, 1998).

The Wnt pathway is highly conserved and instrumental in the embryogenesis and tissue maintenance (Reya et al, 2003; Willert et al, 2003). Activation of the $\mathrm{Wnt} / \beta$-catenin pathway has been

\footnotetext{
*Correspondence: Dr H-F Tien; E-mail: hftien@ntu.edu.tw

${ }^{7}$ These authors contributed equally to this work.

Received 2 August 2011; revised 10 October 2011; accepted II

October 201 I; published online 17 November 201 I
}

shown to be crucial for the establishment of normal and leukaemic stem cells (Austin et al, 1997; Reya et al, 2003; Wang et al, 2010). Dysregulation of Wnt signalling pathway is linked with several types of cancers, including AML (Korinek et al, 1997; Morin et al, 1997; Polakis, 2000; Chung et al, 2002; Clements et al, 2002; Reya and Clevers, 2005; Ysebaert et al, 2006). Chronic activation of Wnt pathway genes resulting from either aberrant overexpression of these genes or loss of natural Wnt inhibitors promotes uncontrolled cell growth and survival (Barker and Clevers, 2006). The Wnt signalling pathway is controlled by several natural Wnt inhibitors including Dickkopfs (DKK), secreted frizzled related proteins (SFRP), Wnt inhibitory factor-1 (Wif-1), human Dapper protein-1 (HDPR1), and so on. Abnormal activation of Wnt signalling by epigenetic silencing of these natural inhibitors was found in human cancers (Suzuki et al, 2004). Association between hypermethylation of some Wnt inhibitors and specific chromosomal translocations in AML was reported in a few studies (Chim et al, 2006; Suzuki et al, 2007; Jost et al, 2008), but not in others (Valencia et al, 2009). Furthermore, the association between hypermethylation of Wnt inhibitors and molecular gene alterations, especially the mutations recently detected, has not been reported. In this study, we aimed to investigate the role of hypermethylation of Wnt inhibitors in adult patients afflicted with AML. To the best of our knowledge, this is the first study to comprehensively address the association of hypermethylation of 
Wnt inhibitors with various genetic mutations in a large cohort of patients with de novo AML. We found distinct association between hypermethylation of certain Wnt inhibitors and specific genetic alterations, mostly Class II mutations, in the leukaemogenesis.

\section{MATERIALS AND METHODS}

\section{Subjects}

From April 1996 to June 2007, a total of 269 adult patients who were newly diagnosed as having de novo AML and had adequate samples for methylation analysis at the National Taiwan University Hospital (NTUH) were enrolled. Among 269 patients, 219 (81.4\%) patients received intensive induction chemotherapy (Idarubicin $12 \mathrm{mg} \mathrm{m}^{-2}$ per day on days $1-3$ and Cytarabine $100 \mathrm{mg} \mathrm{m}^{-2}$ per day on days $1-7$ ) and then consolidation chemotherapy with 2-4 courses of high-dose Cytarabine ( $2000 \mathrm{mg} \mathrm{m}^{-2} \mathrm{q} 12 \mathrm{~h}$ days $1-4$, total eight doses), with or without an anthracycline if complete remission (CR) was achieved (Tang et al, 2009; Hou et al, 2010). The remaining 50 patients received low-dose chemotherapy and/or supportive care because of the poor performance status or the patients' will. This study was approved by the Institutional Review Board of the NTUH, and written informed consent was obtained from all the participants in accordance with the Declaration of Helsinki Principles.

\section{Methylation-specific polymerase chain reaction (MSP)}

Bone marrow (BM) samples were obtained from all the patients at diagnosis. High-molecular-weight DNA was prepared from mononuclear cells as described previously (Tien et al, 1994). A CpG island is defined as a region with at least $200 \mathrm{bp}$ and with a GC percentage greater than $50 \%$ and an observed/expected $\mathrm{CpG}$ ratio greater than $60 \%$ (Gardiner-Garden and Frommer, 1987). The primer sets for the analyses of Wnt inhibitor hypermethylation were designed by the help of the UCSC Genome Browser website (Kent et al, 2002), and the locations of these primers and the regions of the Wnt inhibitors analysed are shown in Supplementary Table 1. Methylation status of the CpG islands in the SFRP1, SFRP2, SFRP4, SFRP5, HDPR1, Wif-1, and $D K K 1$ gene promoters was determined by bisulfite treatment of genomic DNA followed by MSP as reported (Herman et al, 1996; Tien et al, 2001; Roman-Gomez et al, 2007). The method consists of two steps: modification of DNA using sodium bisulphite, which converts all unmethylated, but not methylated, cytosine to uracil, and amplification of the bisulphite-modified DNA by PCR using specific primers. Primer sequences of each gene for the unmethylated and methylated reactions are shown in Supplementary Table 2. Approximately $1 \mu \mathrm{g}$ DNA was sodium bisulphite-modified and subjected to MSP with primers specifically recognising the unmethylated or the methylated sequences of Wnt inhibitor, respectively, by EZ DNA Methylation-GOLD KIT (ZYMO Research, Orange, CA, USA). Polymerase chain reactions were run in a final volume of $25 \mu$ l containing $20 \mathrm{ng}$ bisulphite-treated DNA, $200 \mathrm{nmoll}^{-1}$ deoxynucleotide triphosphate, $150 \mathrm{nmoll}^{-1}$ of each primer, $1 \mathrm{U}$ of AmpliTaq Gold polymerase and buffer (Applied Biosystems, Foster City, CA, USA). Polymerase chain reactions was carried out by heating at $95^{\circ} \mathrm{C}$ for $10 \mathrm{~min}$, followed by 35 cycles of $95^{\circ} \mathrm{C}$ for $30 \mathrm{~s}, 61^{\circ} \mathrm{C}$ for $30 \mathrm{~s}$, and $72{ }^{\circ} \mathrm{C}$ for $30 \mathrm{~s}$, with a final step for 10 min at $72{ }^{\circ} \mathrm{C}$. Polymerase chain reaction products were separated on $2 \%$ agarose gels and visualised by Ethidium bromide staining. Raji cells treated in vitro with SssI methyltransferase (New England Biolabs, Beverly, MA, USA) in order to generate methylated DNA were served as a positive control and BM mononuclear cells from healthy BMT donors were used as negative controls.

\section{Cytogenetics}

Bone marrow cells were harvested directly or after 1-3 days of unstimulated culture as described previously (Tien et al, 1995). Metaphase chromosomes were banded by trypsin-Giemsa technique and karyotyped according to the International System for Human Cytogenetic Nomenclature.

\section{Immunophenotype analysis}

A panel of monoclonal antibodies to myeloid-associated antigens, including CD13, CD33, CD11b, CD15, CD14, and CD41a, as well as lymphoid-associated antigens, including CD2, CD5, CD7, CD19, CD10, and CD20, and lineage nonspecific antigens HLA-DR, CD34, and CD56 were used to characterise the phenotypes of the leukaemia cells as previously described (Tien et al, 1995; Chou et al, 2006).

\section{Mutation analysis}

Mutation analyses of 13 relevant molecular marker genes, NPM1 (Falini et al, 2005), CEBPA (Lin et al, 2005), FLT3/ITD (Shih et al, 2002), FLT3/TKD (Shih et al, 2004), N-RAS, K-RAS (Chen et al, 2006), JAK2 (Chen et al, 2006), KIT (Chen et al, 2007), AML1/ RUNX1 (Tang et al, 2009), MLL/PTD (Shiah et al, 2002), PTPN11 (Hou et al, 2008), ASXL1 (Chou et al, 2010), and WT1 (Hou et al, 2010) were performed as previously described.

\section{Statistical analysis}

The association between chromosomal abnormalities/gene mutations and the Wnt inhibitor hypermethylation was analysed using the Monte Carlo simulation-based Fisher's exact tests. That is, the statistical significance was calculated using a Monte Carlo simulation corrected for multiple hypothesis testing (each with 10000 simulations and with a prior type-I error $\alpha=0.01$ ). MannWhitney $U$-tests were used to compare continuous variables and medians of distributions. To evaluate the impact of Wnt hypermethylation on clinical outcome, only the 219 patients who received standard chemotherapy as mentioned above were included in the analysis. Overall survival (OS) was measured from the date of first diagnosis to the date of last follow-up or death from any cause, whereas relapse-free status indicated that the patient achieved CR and did not relapse by the end of this study. Kaplan-Meier estimation was used to plot survival curves, and log-rank tests were used to test the difference between groups. The Monte Carlo simulation-based Fisher's exact tests were conducted using StatXact-8 (Cytel Inc., Cambridge, MA, USA), and other statistical analyses were performed with the SPSS 16 software (SPSS Inc., Chicago, IL, USA) and Statsdirect (Altrincham, Cheshire, UK).

\section{RESULTS}

\section{Methylation in promoters of Wnt inhibitors in AML patients}

The frequencies of hypermethylation of Wnt inhibitors (in descending order) were as follows: $31.6 \%$ for SFRP1, 30.1\% for DKK1, 26.0\% for Wif-1, 19.3\% for SFRP2, 12.6\% for SFRP5, and 1.5\% for SFRP4. Taken together, 166 AML patients $(61.7 \%)$ had promoter hypermethylation of at least one Wnt inhibitor at diagnosis. A half (83 out of 166) of them had hypermethylation of two or more Wnt inhibitors. No abnormal methylation was found in HDPR1. Hypermethylation of at least one SFRP gene occurred in $40.1 \%(n=108)$ of the AML patients. Aberrant methylation of SFRP1, SFRP2, and SFRP5 was closely associated with each other (all $P<0.0001$ ). DKK1 hypermethylation frequently occurred concomitantly with hypermethylation of SFRP family $(P<0.0001)$, but not Wif-1 $(P=0.7645)$.

\section{Clinical characteristics of patients with aberrant methylation of Wnt inhibitors}

The comparison of clinical characteristics of patients with and without promoter hypermethylation of at least one Wnt inhibitor 
is shown in Table 1. Patients with FAB M0 subtype of AML had the highest incidence $(100 \%)$ of hypermethylation of Wnt inhibitors, whereas those with M4/M5 subtype had the lowest incidence (47.3\%, $P=0.0006)$. For better delineation of the clinical impact of hypermethylation of specific Wnt inhibitor, we analysed the association of individual Wnt inhibitor hypermethylation with clinical characteristics, respectively (Table 2). SFRP hypermethylation occurred more frequently in the patients with AML M0 (87.5\% of M0 patients $v s 38.7 \%$ of others, $P=0.0079$ ), but was less in M4/M5 subtype (27.5\% of M4/M5 vs $49.1 \%$ of others, $P=0.0009)$. DKK1 methylation was also more common in AML M0 subtype $(75 \%$ vs $28.7 \%, P=0.0104)$. On the contrary, Wif- 1 methylation was preferentially found in AML M1 and M3 (42.1\% of M1 vs $21.7 \%$ of others, $P=0.0035$ and $63.2 \%$ of M3 $v s 23.2 \%$ of others, $P=0.0005$, respectively).

Table I Comparison of clinical and laboratory characteristics between AML patients with and without promoter hypermethylation of Wnt inhibitors

\begin{tabular}{|c|c|c|c|}
\hline \multirow[b]{2}{*}{ Characteristics } & \multicolumn{2}{|c|}{ Wnt inhbitors } & \multirow[b]{2}{*}{$P$-value } \\
\hline & Methylated $^{\mathrm{a}}$ & Non-methylated & \\
\hline $\begin{array}{l}\text { Patient no. } \\
\text { Age (years) }\end{array}$ & 166 & 103 & \\
\hline Age (years) & $47.5(15-87)$ & $48(15-87)$ & 0.7989 \\
\hline Gender & & & 0.023 \\
\hline Male & 103 & 49 & \\
\hline Female & 63 & 54 & \\
\hline \multicolumn{3}{|l|}{ FAB classification ${ }^{c}$} & 0.0082 \\
\hline MO & $8(4.8)$ & $0(0)$ & 0.0254 \\
\hline MI & $39(23.5)$ & $18(17.5)$ & 0.2836 \\
\hline M2 & $54(32.5)$ & $31(30.1)$ & 0.6885 \\
\hline M3 & $15(9.0)$ & $4(3.9)$ & 0.1429 \\
\hline M4 & 37 (22.2) & 41 (39.8) & 0.0024 \\
\hline M5 & $6(3.6)$ & $7(6.8)$ & 0.2544 \\
\hline M6 & $4(2.4)$ & $2(1.9)$ & $>0.999$ \\
\hline M7 & 0 & 0 & \\
\hline Unclassified & $3(100)$ & $0(0)$ & \\
\hline WBC $\left(\times 10^{6} \text { per I }\right)^{b}$ & $15950(310-352300)$ & $54470(300-627800)$ & $P<0.0001$ \\
\hline Blast $\left(\times 10^{6} \text { per I }\right)^{b}$ & $7132(0-348777)$ & $32584(0-456725)$ & $P<0.0001$ \\
\hline $\mathrm{LDH}\left(\mathrm{UI}^{-1}\right)^{\mathrm{b}}$ & $859(250-7734)$ & $1273(283-15000)$ & 0.0003 \\
\hline $\mathrm{Hb}\left(\mathrm{g} \mathrm{dl}^{-1}\right)^{b}$ & $7.9(2.9-13.9)$ & $7.8(3.3-14)$ & 0.6952 \\
\hline PIt $\left(\times 10^{9} \text { per I }\right)^{\mathrm{b}}$ & $40(5-802)$ & $46(6-268)$ & 0.2331 \\
\hline
\end{tabular}

Abbreviations: $A M L=$ acute myeloid leukaemia; $F A B=$ French-American-British; $\mathrm{Hb}=$ haemoglobin; $\mathrm{LDH}=$ lactate dehydrogenase; $\mathrm{Plt}=$ platelet; $\mathrm{WBC}=$ white blood cell. ${ }^{a}$ Hypermethylation of at least one Wnt inhibitor. ${ }^{b}$ Median (range). ${ }^{c}$ No of patients (\%)
Male patients had a higher incidence of hypermethylation of Wnt inhibitors than females $(62.0 \%$ vs $47.6 \%, P=0.023)$. Patients with hypermethylation of at least one Wnt inhibitor had lower WBC counts, blast counts and serum lactate dehydrogenase (LDH) levels at diagnosis. SFRP-5 hypermethylation alone was associated with higher platelet counts $(P=0.0144)$.

\section{Correlation between promoter hypermethylation of Wnt inhibitors and immunophenotypes of leukaemic cells}

Promoter hypermethylation of any Wnt inhibitor as a whole was positively associated with the expression of HLA-DR $(P=0.0385)$, CD19 $(P=0.0026)$, and CD34 $(P=0.005)$, but was inversely associated with the expression of $\operatorname{CD} 14(P=0.0237)$ on the leukaemic cells (Supplementary Table 3 ). There was no difference in the expression of other antigens between the patients with and without Wnt inhibitor methylation.

Acute myeloid leukaemia patients with hypermethylation of any SFRP gene as a whole had higher frequency of CD19 $(P=0.0004)$, CD7 $(P=0.0144)$, and CD34 expression $(P=0.012)$, but had lower frequency of $\mathrm{CD} 14$ expression $(P=0.0395)$ on the leukaemia cells. For individual SFRP, hypermethylation of SFRP1 had similar pattern of association with antigen expression to that of SFRP as a whole (Supplementary Table 5). SFRP2 hypermethylation showed no association with the expression of any antigen studied, whereas SFRP5 hypermethylation had close association with CD11b and CD7 expression, but had inverse correlation with CD33 expression. On the other hand, DKK1 methylation was positively associated with HLA-DR $(P=0.0273)$, CD34 $(P=0.0002)$, and CD56 expression $(P=0.0238)$, and Wif-1 methylation was positively associated with CD7 $(P=0.0004)$, but was inversely associated with CD14 $(P=0.0377)$ and CD33 expression $(P=0.0383)$.

\section{Association of aberrant methylation of Wnt inhibitors with cytogenetic abnormalities}

Chromosome data were available in 260 patients at diagnosis, including 157 with and 103 without hypermethylation of Wnt inhibitors (Table 3 and Supplementary Table 3). Hypermethylation of any Wnt inhibitor as a whole occurred more frequently in patients with favourable karyotype (79.4\%) than in those with intermediate-risk $(52.4 \%)$ or unfavourable cytogenetics $(67.7 \%$, $P=0.0005$ ), and more frequently in patients with abnormal cytogenetics than in those with normal karyotype (69\% vs $50.8 \%$, $P=0.0034)$. It was also positively associated with $\mathrm{t}(8 ; 21)$ $(P=0.0014)$. Hypermethylation of any $S F R P$ as a whole was closely associated with favourable cytogenetics $(P=0.0132)$ and $\mathrm{t}(8 ; 21) \quad(P<0.0001)$, but negatively correlated with intermediate

Table 2 Summary of correlation between hypermethylation of Wht inhibitors and clinical and laboratory features

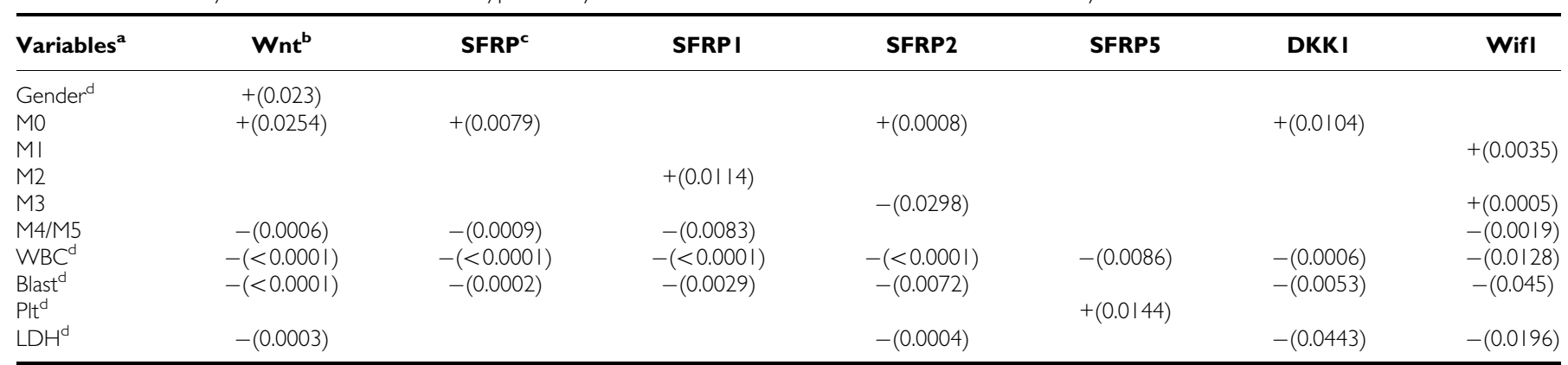

Abbreviations: blank = no significant association; $L D H=$ lactate dehydrogenase; plt = platelet; $+=$ positive association $\left(P\right.$-value); $-=$ negative association $\left(P\right.$-value). ${ }^{a}$ No significant correlation of hypermethylation of Wnt inhibitors with age and haemoglobin level, which were not shown in this table. 'bypermethylation of any Wnt inhibitors including SFRP, Wif-I, and DKKI. ' Hypermethylation of any SFRP gene including SFRPI, SFRP2, SFRP4, and SFRP5. 'Gender (correlation with male); white blood cells, blast, platelet, and LDH (correlation with high level). 
Table 3 Association of hypermethylation of Wnt inhibitors with chromosomal abnormalities ${ }^{2}$

\begin{tabular}{|c|c|c|c|c|c|c|c|c|c|c|c|c|}
\hline & \multicolumn{2}{|c|}{ No. of patients (\%) } & \multicolumn{3}{|c|}{ No. of patients (\%) } & \multicolumn{3}{|c|}{ No. of patients (\%) } & \multicolumn{3}{|c|}{ No of patients (\%) } & \multirow[b]{3}{*}{$P$-value } \\
\hline & \multirow{2}{*}{$\begin{array}{c}\begin{array}{c}\text { Wnt } \\
\text { methylated }\end{array} \\
N=158\end{array}$} & \multirow{2}{*}{$\begin{array}{c}\begin{array}{c}\text { Wnt } \\
\text { unmethylated }\end{array} \\
N=102\end{array}$} & \multirow[b]{2}{*}{$P$-value } & \multirow{2}{*}{$\begin{array}{c}\begin{array}{c}\text { SFRP } \\
\text { methylated }^{\mathbf{c}}\end{array} \\
N=101\end{array}$} & \multirow{2}{*}{$\begin{array}{c}\begin{array}{c}\text { SFRP } \\
\text { unmethylated }\end{array} \\
N=159\end{array}$} & \multirow[b]{2}{*}{$P$-value } & \multirow{2}{*}{$\begin{array}{c}\begin{array}{c}\text { SFRP I } \\
\text { methylated }\end{array} \\
\mathbf{N}=\mathbf{8 2}\end{array}$} & \multirow{2}{*}{$\begin{array}{c}\begin{array}{c}\text { SFRPI } \\
\text { unmethylated }\end{array} \\
N=I 78\end{array}$} & \multirow[b]{2}{*}{$P$-value } & \multirow{2}{*}{$\begin{array}{c}\begin{array}{c}\text { SFRP2 } \\
\text { methylated }\end{array} \\
N=47\end{array}$} & \multirow{2}{*}{$\begin{array}{c}\begin{array}{c}\text { SFRP2 } \\
\text { unmethylated }\end{array} \\
N=213\end{array}$} & \\
\hline & & & & & & & & & & & & \\
\hline avourable ${ }^{d}$ & $50(31.6)$ & $13(12.7)$ & 0.001 & 34 (33.7) & $29(18.2)$ & 0.0132 & $28(34.1)$ & $35(19.7)$ & 0.0196 & $7(\mid 4.9)$ & $56(26.3)$ & 0.0685 \\
\hline Intermediate & $87(55.1)$ & $79(77.5)$ & $<0.0001$ & $52(5 \mid .5)$ & 114 (7I.7) & 0.0002 & $41(50)$ & $125(70.2)$ & 0.0029 & $28(59.6)$ & $138(64.8)$ & 0.2067 \\
\hline$U_{\text {nfavourable }}^{d}$ & $21(13.3)$ & $10(9.8)$ & 0.5575 & $15(14.9)$ & $16(10.1)$ & 0.3357 & $13(15.9)$ & $18(10.1)$ & 0.2187 & $12(25.5)$ & $19(8.9)$ & 0.0069 \\
\hline$t(8 ; 2 I)$ & $27(\mid 7.1)$ & $4(3.9)$ & 0.0014 & $23(22.8)$ & $8(5.0)$ & $<0.0001$ & $21(25.6)$ & $10(5.6)$ & $<0.0001$ & $3(6.4)$ & $28(13.1)$ & 0.3175 \\
\hline $\mathrm{t}(15 ; 17)$ & $15(9.5)$ & $4(3.9)$ & 0.1414 & $6(5.9)$ & $13(8.2)$ & 0.6276 & $3(3.7)$ & $16(9.0)$ & 0.1979 & $0(0)$ & $19(8.9)$ & 0.0293 \\
\hline $\operatorname{lnv}(16)^{\prime}$ & $8(5.1)$ & $5(4.9)$ & $>0.9999$ & $5(5.0)$ & $8(5.0)$ & $>0.9999$ & $4(4.9)$ & $9(5.1)$ & $>0.9999$ & $4(8.5)$ & $9(4.2)$ & 0.2612 \\
\hline $\mathrm{t}(\mathrm{I} \mid \mathrm{q} 23)$ & $4(2.5)$ & $6(5.9)$ & 0.1971 & $3(3.0)$ & $7(4.4)$ & 0.7449 & I (1.2) & $9(5.1)$ & 0.1779 & $2(4.3)$ & $8(3.8)$ & $>0.9999$ \\
\hline Normal & $60(38)$ & $58(56.9)$ & 0.0034 & $35(34.7)$ & $83(52.2)$ & 0.0072 & $28(34.1)$ & $90(50.6)$ & 0.0158 & $17(36.2)$ & 101 (47.4) & 0.1958 \\
\hline Complex & $16(10.1)$ & $7(6.9)$ & 0.503 & $13(12.9)$ & $10(6.3)$ & 0.0765 & $1 \mid(13.4)$ & $12(6.7)$ & 0.0993 & II (23.4) & $12(5.6)$ & 0.0006 \\
\hline
\end{tabular}

\begin{tabular}{|c|c|c|c|c|c|c|c|c|c|}
\hline & \multicolumn{2}{|c|}{ No. of patients (\%) } & & \multicolumn{2}{|c|}{ No. of patients (\%) } & \multicolumn{3}{|c|}{ No. of patients (\%) } & \multirow[b]{3}{*}{$P$-value } \\
\hline & $\begin{array}{c}\text { SFRP5 } \\
\text { methylated }\end{array}$ & $\begin{array}{c}\text { SFRP5 } \\
\text { unmethylated }\end{array}$ & & $\begin{array}{c}\text { DKKI } \\
\text { methylated }\end{array}$ & $\begin{array}{c}\text { DKKI } \\
\text { unmethylated }\end{array}$ & & $\begin{array}{c}\text { Wif-I } \\
\text { methylated }\end{array}$ & $\begin{array}{c}\text { Wif-I } \\
\text { unmethylated }\end{array}$ & \\
\hline & $\mathbf{N}=\mathbf{3} \mathbf{I}$ & $\mathbf{N}=\mathbf{2 2 9}$ & $P$-value & $N=75$ & $N=185$ & $P$-value & $N=68$ & $N=192$ & \\
\hline Favourable $^{d}$ & $7(22.6)$ & $56(24.5)$ & 0.8294 & $27(36)$ & $36(19.5)$ & 0.0179 & $14(20.6)$ & $49(25.5)$ & 0.5128 \\
\hline Intermediate ${ }^{d}$ & $18(58.1)$ & $148(64.6)$ & 0.2644 & $36(48)$ & $130(78.3)$ & 0.0002 & $47(69.1)$ & $119(62)$ & 0.3181 \\
\hline Unfavourable $e^{d}$ & $6(19.4)$ & $25(10.9)$ & 0.2494 & $12(16)$ & $19(70.3)$ & 0.2995 & $7(10.3)$ & $24(12.5)$ & 0.828 \\
\hline$t(8 ; 21)$ & $2(6.5)$ & $29(12.7)$ & 0.5523 & $20(26.7)$ & | (5.9) & $<0.0001$ & $0(0)$ & $31(16.1)$ & $<0.0001$ \\
\hline$t(15 ; 17)$ & $4(12.9)$ & $15(6.6)$ & 0.2584 & $2(2.7)$ & $17(9.2)$ & 0.1109 & $12(17.6)$ & $7(3.6)$ & 0.0005 \\
\hline $\ln v(16)$ & ( $(3.2)$ & $12(5.2)$ & $>0.9999$ & $5(6.7)$ & $8(4.3)$ & 0.5302 & $2(2.9)$ & II (5.7) & 0.5238 \\
\hline $\mathrm{t}(\mathrm{I} \mid \mathrm{q} 23)$ & $0(0)$ & $10(45.4)$ & 0.6135 & $0(0)$ & $10(5.4)$ & 0.0673 & $2(2.9)$ & $8(4.2)$ & $>0.9999$ \\
\hline Normal & $14(45.2)$ & $104(45.4)$ & $>0.9999$ & $23(30.7)$ & $95(51.4)$ & 0.0025 & $31(45.6)$ & $87(45.3)$ & $>0.9999$ \\
\hline Complex & $5(|6|)$. & $18(7.9)$ & 0.1679 & $9(12)$ & $14(7.6)$ & 0.3339 & $6(8.8)$ & $17(8.9)$ & $>0.9999$ \\
\hline
\end{tabular}

No significant correlation between hypermethylation of Wht inhibitors and $+8,+11,+13,+21,-7 / 7 q^{-}$, and $-5 / 5 q^{-}$, which were not shown in this table. The $P$-value was

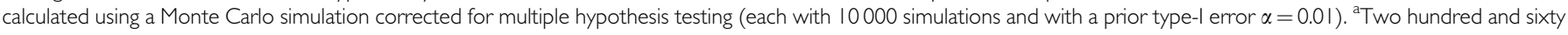
patients, including 158 Wnt-methylated and 102 Wnt-unmethylated patients, had chromosome data at diagnosis. Hypermethylation of SFRP4 was not included in the table

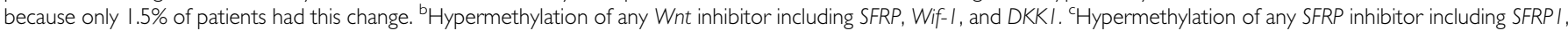
SFRP2, SFRP4, and SFRP5. 'Favourable, t(I5; I7), t(8;2I), inv (I6); unfavourable, -7, del(7q), -5, del(5q), 3q abnormality, complex abnormalities; Intermediate, normal karyotype and other abnormalities.

cytogenetics $(P=0.0002)$ and normal karyotype $(P=0.0072)$. For individual SFRP, hypermethylation of SFRP1 had the same pattern of association with cytogenetic changes as that of SFRP as a whole (Table 3 and Supplementary Table 4). On the other side, hypermethylation of SFRP2 was positively associated with unfavourable $(P=0.0069)$ and complex cytogenetic $(P=0.0006)$, but was inversely correlated with $\mathrm{t}(15 ; 17)(P=0.0293)$. DKK1 hypermethylation was detected more frequently in patients with favourable cytogenetics $(P=0.0179)$ and $\mathrm{t}(8 ; 21)(P<0.0001)$, but was less common in patients with intermediate cytogenetics $(P=0.0002)$ and normal karyotype $(P=0.0025)$. Wif- 1 hypermethylation was more frequently detected in the patients with $t(15 ; 17)$ than in other cytogenetic changes $(63.2 \%$ of M3 vs $23.2 \%$ of others, $P=0.0005)$, but was seldom found in the patients with $\mathrm{t}(8 ; 21)(0 \%$ vs $29.7 \%, P<0.0001)$. There was no association of hypermethylation of Wnt inhibitors with other chromosomal abnormalities, including $+8,+11,+13,+21,-5 / \operatorname{del}(5 q)$, and $-7 / \operatorname{del}(7 q)$.

\section{Association of promoter hypermethylation of Wnt inhibitors with molecular gene mutations}

Among the 166 patients with hypermethylation of any Wnt inhibitor, $145(87.3 \%)$ patients showed concurrent molecular mutation of at least one gene at diagnosis (Table 4); 98 patients had one gene mutation, 35 had two, 10 had three and 2 patients had four gene mutations. In total, 100 patients $(68.5 \%)$ had concurrently at least one Class II mutation, including $M L L / \mathrm{PTD}$,
CEBPA, and $A M L 1 / R U N X 1$ mutations, $\mathrm{t}(8 ; 21), \mathrm{t}(15 ; 17)$, inv (16), and $\mathrm{t}(11 \mathrm{q} 23)$.

Patients with at least one Wnt inhibitor hypermethylation had a trend of higher incidence of CEBPA mutation than those without hypermethylation $(16.9 \%$ vs $8.7 \%, P=0.0693)$, but had significantly lower incidence of FLT3/ITD and NPM1 mutations $(17.5 \%$ vs $34 \%, P=0.003$ and $12.7 \%$ vs $36.9 \%, P<0.0001$, respectively).

Among the 108 patients with SFRP methylation as a whole, 92 (85.2\%) showed concurrent molecular gene mutations at diagnosis; 60 had one gene mutation, 23 had two, 7 had three, and 2 patients had four mutations. Sixty-nine (75.0\%) of them had at least one Class II mutation concurrently. Patients with SFRP hypermethylation had a significantly lower incidence of NPM1 mutation than those without the gene hypermethylation $(11.1 \% \mathrm{vs}$ $29.2 \%, P=0.0005$, Table 4 and Supplementary Table 3$)$. There was no difference in the incidence of other molecular gene mutations between patients with and without SFRP methylation. For individual $S F R P$, hypermethylation of $S F R P 1$ was negatively associated with NPM1 mutation, whereas that of SFRP2 was closely associated with $A M L 1 / R U N X 1$ mutation, but negatively correlated with NPM1 mutation, and SFRP5 hypermethylation was positively associated with $M L L /$ PTD (Table 4 and Supplementary Table 4).

Among the 70 patients with Wif-1 methylation, 60 (85.7\%) patients showed concomitant molecular gene mutations at diagnosis; 46 had one gene mutation, 10 had two and 4 patients had three. Of these, 38 (63.3\%) had concurrently at least one Class II mutation. Patients with Wif-1 hypermethylation had a significantly higher incidence of CEBPA mutation $(28.6 \%$ vs $8.5 \%, P<0.0001$, Table 4 and 
Table 4 Association of hypermethylation of Wnt inhibitors with molecular gene mutations ${ }^{a}$

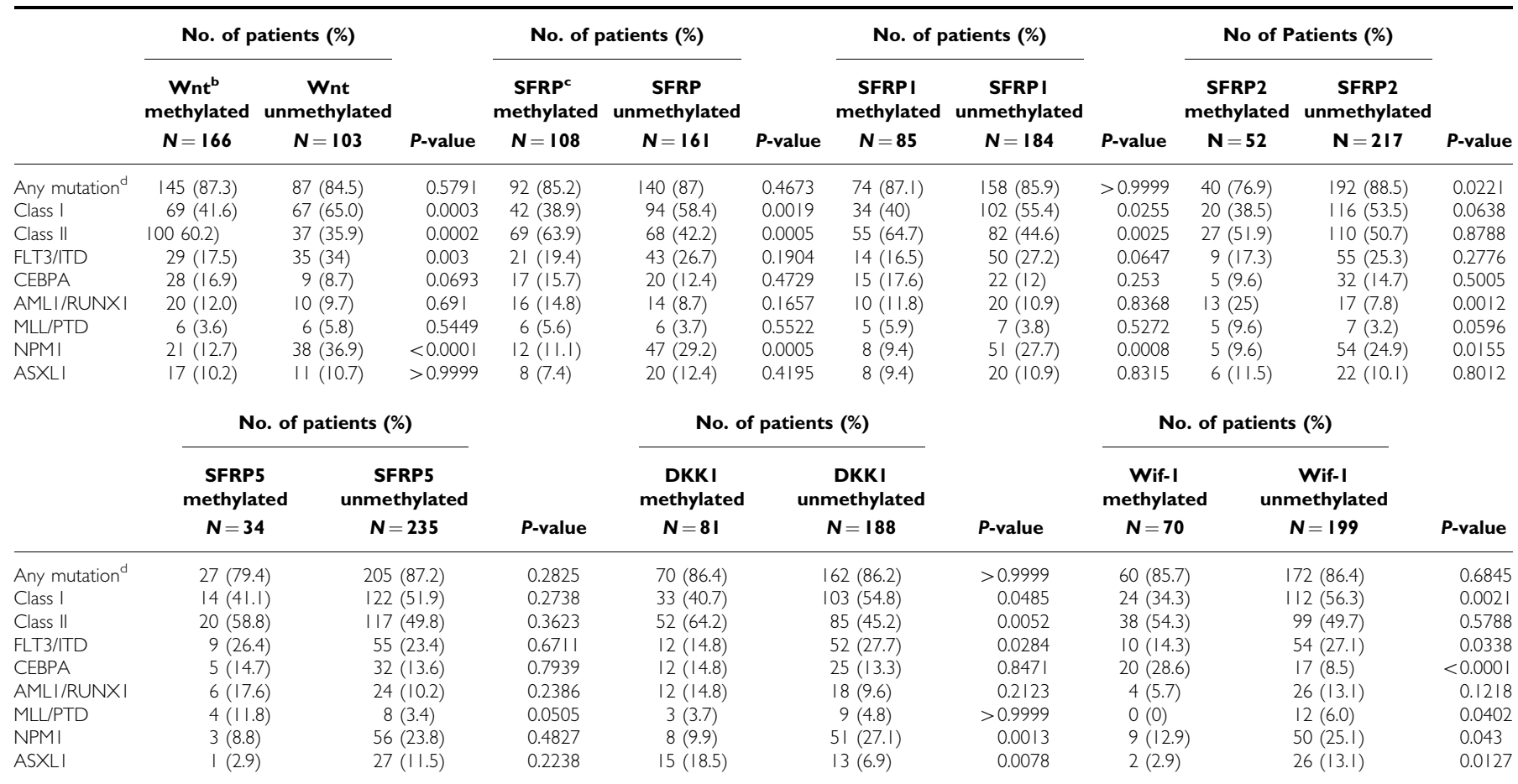

Abbreviations: Class I, Class I mutations including FLT3/ITD, FLT3/TKD, NRAS, KRAS, KIT, JAK2, and PTPNI I mutations; Class II, Class II mutations including MLL/PTD, CEBPA, and AMLI/RUNXI mutations. $\mathrm{t}(8 ; 2 \mid), \mathrm{t}(15 ; 17)$, inv (I6), and $\mathrm{t}(\mathrm{I}$ | q23). The $P$-value was calculated using a Monte Carlo simulation corrected for multiple hypothesis testing (each with 10000 simulations and with a prior type-I error $\alpha=0.01$ ). ${ }^{a}$ No significant correlation between hypermethylation of Wnt inhibitors and FLT3/TKD, KIT, NRAS, KRAS, JAK2, and PTPNII mutations, which were not shown in this table. 'Hypermethylation of any Wnt inhibitors including SFRP, Wif-I, and DKKI. 'Hypermethylation of any SFRP gene including SFRPI, SFRP2, SFRP4, and SFRP5. 'Any mutation included the mutation of any Class I, Class II, or others, such as NPMI, WTI, and ASXLI mutations.

Supplementary Table 4), but had lower incidences of FLT3/ITD, $M L L / P T D, N P M 1$ mutations, and ASXL1 mutations (14.3\% vs $27.1 \%$, $P=0.0338 ; 0 \%$ vs $5.7 \%, P=0.0402 ; 12.9 \%$ vs $25.1 \%, P=0.043$; and $2.9 \%$ vs $13.1 \%, P=0.0127$, respectively) than those without the gene hypermethylation.

Among the 81 patients with $D K K 1$ hypermethylation, 70 (86.4\%) showed concurrent gene mutations at diagnosis (Table 4 and Supplementary Table 4); 41 had one gene mutation, 23 had two, and 6 had three. Out of these, $52(73.2 \%)$ had at least one Class II mutation concurrently. Patients with $D K K 1$ hypermethylation had a significantly higher incidence of ASXL1 mutation (18.5\% vs $6.9 \%$, $P=0.0078$ ), but lower incidences of FLT3/ITD and NPM1 mutations than those without the gene hypermethylation $(14.8 \%$ vs $27.7 \% P=0.0284$ and $9.9 \%$ vs $27.1 \%, P=0.0013$, respectively).

\section{Impact of promoter hypermethylation of Wnt inhibitors on response to therapy and clinical outcome}

Of the 219 AML patients undergoing conventional induction chemotherapy, $184(84.0 \%)$ patients achieved a CR. With a median follow-up time of 32 months, the identified poorer prognostic factors for OS included older age $(P<0.001)$, unfavourable cytogenetics $(P<0.001)$, FLT3/ITD $(P=0.03)$, and AML1/RUNX1 mutations $(P=0.039)$. However, hypermethylation of at least one Wnt inhibitor or methylation of any SFRP did not influence the CR rate, relapse rate, OS, and relapse-free survival (RFS). Further evaluation of the effect of hypermethylation of individual Wnt inhibitors, including SFRP1, SFRP2, SFRP5, DKK1, and Wif-1 showed the same findings. Subgroup analyses in patients with favourable, intermediate, or unfavourable-risk cytogenetics, and in patients with normal karyotype or those with specific gene mutations could not demonstrate prognostic impact of hypermethylation of Wnt inhibitors. The number of genes hypermethylated also did not affect the treatment response.

\section{DISCUSSION}

In this study, we showed that aberrant promoter methylation of Wnt inhibitors was closely associated with specific cytogenetic abnormalities and molecular gene alterations in the patients afflicted with de novo AML. Most of the AML patients harbouring Wnt inhibitors hypermethylation had concurrent Class II mutations at diagnosis. Furthermore, aberrant Wnt inhibitor methylation was closely associated with male, FAB M0 subtype, lower WBC and blast counts and lower LDH levels, but inversely associated with M4/M5 subtype.

Few studies have focused on the correlation of hypermethylation of Wnt inhibitors with specific cytogenetic abnormalities. To the best of our knowledge, there has been no report concerning the association between hypermethylation of Wnt inhibitors and molecular gene mutations till now. This study recruited a large cohort of de novo adult AML patients for analyses of the association between abnormal promoter methylation of Wnt inhibitors and genetic alterations. We found that hypermethylation of Wnt inhibitors occurred predominantly in the patients with abnormal cytogenetics, especially in the favourable-risk group. In addition to the close association of SFRP1 and DKK1 hypermethylation with $\mathrm{t}(8 ; 21)$ and Wif-1 hypermethylation with $\mathrm{t}(15 ; 17)$ (Tables 3 and 4), we found for the first time the close association of Wif-1 hypermethylation with CEBPA mutation, SFRP2 hypermethylation with $A M L 1 / R U N X 1$ mutation, SFRP5 hypermethylation with $M L L / \mathrm{PTD}$, and DKK1 hypermethylation with $A S X L 1$ mutation. These results further support the hypothesis that epigenetic alterations may cooperate with genetic alterations in 
the leukaemogenesis of AML. Muller-Tidow et al (2004) demonstrated AML-associated translocation products, such as RUNX1RUNX1T1 and PML-RAR $\alpha$ activated the plakoglobin production, resulting in the accumulation of endogenous $\beta$-catenin in the nucleus and further activation of relevant target genes. Results from this and other studies suggest that downregulation of Wnt inhibitors through promoter hypermethylation might be another mechanism leading to the activation of Wnt signalling pathway in AML with some chromosome translocations and gene mutations, such as $\mathrm{t}(8 ; 21), \mathrm{t}(15 ; 17), M L L / \mathrm{PTD}, A M L 1 / R U N X 1, C E B P A$, and ASXL1 mutations. The reason that these genetic alterations are closely associated with hypermethylation of specific Wnt inhibitors remains elusive.

Although we did not validate our findings by correlating the methylation status with the gene expression, downregulation of the Wnt inhibitors due to abnormal promoter methylation has been demonstrated previously (Roman-Gomez et al, 2007). Furthermore, methylation of Wnt inhibitors was shown to be associated with upregulation of the downstream signalling of the Wnt pathway (Roman-Gomez et al, 2007; Valencia et al, 2009). However, it remains unknown whether the hypermethylation of the Wnt inhibitors examined in this study indeed directly influence the Wnt canonical signalling pathway or the noncanonical pathway activities in AML because Bovolenta et al (2008) showed that SFRPs inhibit both Wnt canonical and non-canonical pathways and different SFRPs may have opposite effect on the same process. Re-expression of methylated Wnt inhibitors and inactivation of the Wnt pathway in the cell lines with aberrant methylation of these Wnt inhibitors were also shown after treatment with the demethylating agent decitabine (Valencia et al, 2009). These findings suggest that Wnt pathway is regulated, at least partially, by methylation of the Wnt inhibitors.

The percentage of patients with aberrant methylation of at least one Wnt inhibitor in this study $(61.7 \%)$ was similar to that reported by Valencia et al (2009). However, the frequencies of aberrant methylation of SFRP1, SFRP2, SFRP4, and SFRP5 (31.6\%, 19.3\%, $1.5 \%$, and $12.6 \%$, respectively; total $40.1 \%$ ) in this study were lower than those $(41 \%, 31 \%, 4 \%$, and $22 \%$, respectively) reported by Valencia et al (2009) who analysed 184 non-M3 AML patients, but were similar to those reported by Jost et al (2008). These probably reflect the difference in patient selection and ethnic diversity.

To investigate the prognostic relevance of abnormal methylation of Wnt inhibitors in AML patients, we focused on the patients receiving standard chemotherapy. However, we did not find the difference of clinical outcome, including CR rate, OS, and RFS, between AML patients with and without Wnt inhibitor hypermethylation. The same were also true in subgroups of patients with different risk cytogenetics or gene mutations. Jost et al (2008) also did not find any prognostic impact of aberrant methylation in $S F R P$ promoters in 100 AML patients. Contrary to our findings, Chim et al (2006) pointed out that Wif-1 methylation was an

\section{REFERENCES}

Austin TW, Solar GP, Ziegler FC, Liem L, Matthews W (1997) A role for the Wnt gene family in hematopoiesis: expansion of multilineage progenitor cells. Blood 89(10): 3624-3635

Barker N, Clevers H (2006) Mining the Wnt pathway for cancer therapeutics. Nat Rev Drug Discov 5(12): $997-1014$

Bovolenta P, Esteve P, Ruiz JM, Cisneros E, Lopez-Rios J (2008) Beyond Wnt inhibition: new functions of secreted Frizzled-related proteins in development and disease. J Cell Sci 121(Pt 6): 737-746

Chen CY, Lin LI, Tang JL, Ko BS, Tsay W, Chou WC, Yao M, Wu SJ, Tseng $\mathrm{MH}$, Tien HF (2007) RUNX1 gene mutation in primary myelodysplastic syndrome-the mutation can be detected early at diagnosis or acquired during disease progression and is associated with poor outcome. $\mathrm{Br} J$ Haematol 139(3): 405-414 independent poor prognostic factor for DFS and Valencia et al (2009) showed AML patients with two or more methylated Wnt inhibitor genes had poorer RFS, but not OS, in the subgroup of patients 60 years or younger with intermediate-risk cytogenetics by multivariate analysis. Large-scale studies with more AML patients are needed to clarify this point.

In summary, our findings address that $\mathrm{CpG}$ island hypermethylation in the promoters of Wnt pathway inhibitors including SFRP family, Wif-1, and DKK1 is a common event in AML. More intriguingly, there is distinct association between aberrant methylation of some Wnt inhibitors and specific genetic alterations, such as close association of DKK1 hypermethylation with $\mathrm{t}(8 ; 21)$ and $A S X L 1$ mutation, Wif-1 hypermethylation with $\mathrm{t}(15 ; 17)$ and CEBPA mutation, SFRP1 hypermethylation with $\mathrm{t}(8 ; 21)$, SFRP2 hypermethylation with AML1/RUNX1 mutation, and SFRP5 methylation with $M L L / P T D$. Epigenetic alterations, such as hypermethylation of Wnt inhibitors, may interact with specific cytogenetic abnormalities or molecular gene mutations, especially Class II mutations, in the leukaemogenesis of AML.

\section{ACKNOWLEDGEMENTS}

This work was partially sponsored by grants NRPB-100CA068, NSC 97-2314-B-002-015-MY3, and 97-2628-B-002-002-MY3 from the National Science Council, Taiwan, Republic of China, DOH99TD-C-111-001 from Department of Health (Taiwan), and NTUH.99S-1369, 99P14, and 100P07 from the Department of Medical Research, National Taiwan University Hospital.

\section{Author contributions}

$\mathrm{H}-\mathrm{AH}$ was responsible for literature collection, study design, data management and interpretation, and manuscript writing; Y-YK was responsible for literature collection, data interpretation, and manuscript writing; C-YL was responsible for statistical analysis and interpretation of the statistical findings; $\mathrm{M}-\mathrm{CL}$ was responsible for laboratory research and interpretation; J-LT, C-YC, W-CC and MY, contributed toward patient samples and clinical data; C-FH, F-YL and M-CL, performed the laboratory research and chromosomal studies and H-FT planned, designed, wrote the manuscript, and coordinated the study over the entire period.

\section{Conflict of interest}

The authors declare no conflict of interest.

Supplementary Information accompanies the paper on British Journal of Cancer website (http://www.nature.com/bjc)
Chen CY, Lin LI, Tang JL, Tsay W, Chang HH, Yeh YC, Huang CF, Chiou RJ, Yao M, Ko BS, Chen YC, Lin KH, Lin DT, Tien HF (2006) Acquisition of JAK2, PTPN11, and RAS mutations during disease progression in primary myelodysplastic syndrome. Leukemia 20(6): $1155-1158$

Chim CS, Chan WW, Pang A, Kwong YL (2006) Preferential methylation of Wnt inhibitory factor-1 in acute promyelocytic leukemia: an independent poor prognostic factor. Leukemia 20(5): 907-909

Chou WC, Huang HH, Hou HA, Chen CY, Tang JL, Yao M, Tsay W, Ko BS, Wu SJ, Huang SY, Hsu SC, Chen YC, Huang YN, Chang YC, Lee FY, Liu MC, Liu CW, Tseng MH, Huang CF, Tien HF (2010) Distinct clinical and biological features of de novo acute myeloid leukemia with additional sex comb-like 1 (ASXL1) mutations. Blood 116(20): 4086-4094 
Chou WC, Tang JL, Lin LI, Yao M, Tsay W, Chen CY, Wu SJ, Huang CF, Chiou RJ, Tseng MH, Lin DT, Lin KH, Chen YC, Tien HF (2006) Nucleophosmin mutations in de novo acute myeloid leukemia: the agedependent incidences and the stability during disease evolution. Cancer Res 66(6): $3310-3316$

Chung EJ, Hwang SG, Nguyen P, Lee S, Kim JS, Kim JW, Henkart PA, Bottaro DP, Soon L, Bonvini P, Lee SJ, Karp JE, Oh HJ, Rubin JS, Trepel JB (2002) Regulation of leukemic cell adhesion, proliferation, and survival by beta-catenin. Blood 100(3): $982-990$

Clements WM, Wang J, Sarnaik A, Kim OJ, MacDonald J, Fenoglio-Preiser C, Groden J, Lowy AM (2002) beta-Catenin mutation is a frequent cause of Wnt pathway activation in gastric cancer. Cancer Res 62(12): 3503-3506

Falini B, Mecucci C, Tiacci E, Alcalay M, Rosati R, Pasqualucci L, La Starza R, Diverio D, Colombo E, Santucci A, Bigerna B, Pacini R, Pucciarini A, Liso A, Vignetti M, Fazi P, Meani N, Pettirossi V, Saglio G, Mandelli F, Lo-Coco F, Pelicci PG, Martelli MF (2005) Cytoplasmic nucleophosmin in acute myelogenous leukemia with a normal karyotype. $N$ Engl J Med 352(3): $254-266$

Gardiner-Garden M, Frommer M (1987) CpG islands in vertebrate genomes. J Mol Biol 196(2): 261 -282

Gilliland DG (2002) Molecular genetics of human leukemias: new insights into therapy. Semin Hematol 39(4 Suppl 3): 6-11

Herman JG, Graff JR, Myohanen S, Nelkin BD, Baylin SB (1996) Methylation-specific PCR: a novel PCR assay for methylation status of CpG islands. Proc Natl Acad Sci USA 93(18): 9821 -9826

Herman JG, Umar A, Polyak K, Graff JR, Ahuja N, Issa JP, Markowitz S, Willson JK, Hamilton SR, Kinzler KW, Kane MF, Kolodner RD, Vogelstein B, Kunkel TA, Baylin SB (1998) Incidence and functional consequences of hMLH1 promoter hypermethylation in colorectal carcinoma. Proc Natl Acad Sci USA 95(12): 6870-6875

Hou HA, Chou WC, Lin LI, Chen CY, Tang JL, Tseng MH, Huang CF, Chiou RJ, Lee FY, Liu MC, Tien HF (2008) Characterization of acute myeloid leukemia with PTPN11 mutation: the mutation is closely associated with NPM1 mutation but inversely related to FLT3/ITD. Leukemia 22(5): $1075-1078$

Hou HA, Huang TC, Lin LI, Liu CY, Chen CY, Chou WC, Tang JL, Tseng MH, Huang CF, Chiang YC, Lee FY, Liu MC, Yao M, Huang SY, Ko BS, Hsu SC, Wu SJ, Tsay W, Chen YC, Tien HF (2010) WT1 mutation in 470 adult patients with acute myeloid leukemia: stability during disease evolution and implication of its incorporation into a survival scoring system. Blood 115(25): 5222-5231

Jones PA, Baylin SB (2002) The fundamental role of epigenetic events in cancer. Nat Rev Genet 3(6): 415-428

Jost E, Schmid J, Wilop S, Schubert C, Suzuki H, Herman JG, Osieka R, Galm O (2008) Epigenetic inactivation of secreted Frizzled-related proteins in acute myeloid leukaemia. Br J Haematol 142(5): 745-753

Kent WJ, Sugnet CW, Furey TS, Roskin KM, Pringle TH, Zahler AM, Haussler D (2002) The human genome browser at UCSC. Genome Res 12(6): $996-1006$

Korinek V, Barker N, Morin PJ, van Wichen D, de Weger R, Kinzler KW, Vogelstein B, Clevers H (1997) Constitutive transcriptional activation by a beta-catenin-Tcf complex in $\mathrm{APC}^{-1-}$ colon carcinoma. Science 275(5307): $1784-1787$

Lin LI, Chen CY, Lin DT, Tsay W, Tang JL, Yeh YC, Shen HL, Su FH, Yao M, Huang SY, Tien HF (2005) Characterization of CEBPA mutations in acute myeloid leukemia: most patients with CEBPA mutations have biallelic mutations and show a distinct immunophenotype of the leukemic cells. Clin Cancer Res 11(4): 1372-1379

McCormack E, Bruserud O, Gjertsen BT (2008) Review: genetic models of acute myeloid leukaemia. Oncogene 27(27): 3765-3779

Morin PJ, Sparks AB, Korinek V, Barker N, Clevers H, Vogelstein B, Kinzler KW (1997) Activation of beta-catenin-Tcf signaling in colon cancer by mutations in beta-catenin or APC. Science 275(5307): 1787-1790

Muller-Tidow C, Steffen B, Cauvet T, Tickenbrock L, Ji P, Diederichs S, Sargin B, Kohler G, Stelljes M, Puccetti E, Ruthardt M, deVos S, Hiebert SW, Koeffler HP, Berdel WE, Serve H (2004) Translocation products in acute myeloid leukemia activate the Wnt signaling pathway in hematopoietic cells. Mol Cell Biol 24(7): 2890-2904

Polakis P (2000) Wnt signaling and cancer. Genes Dev 14(15): $1837-1851$
Renneville A, Roumier C, Biggio V, Nibourel O, Boissel N, Fenaux P, Preudhomme C (2008) Cooperating gene mutations in acute myeloid leukemia: a review of the literature. Leukemia 22(5): 915-931

Reya T, Clevers H (2005) Wnt signalling in stem cells and cancer. Nature 434(7035): $843-850$

Reya T, Duncan AW, Ailles L, Domen J, Scherer DC, Willert K, Hintz L, Nusse R, Weissman IL (2003) A role for Wnt signalling in self-renewal of haematopoietic stem cells. Nature 423(6938): 409-414

Roman-Gomez J, Cordeu L, Agirre X, Jimenez-Velasco A, San Jose-Eneriz E, Garate L, Calasanz MJ, Heiniger A, Torres A, Prosper F (2007) Epigenetic regulation of Wnt-signaling pathway in acute lymphoblastic leukemia. Blood 109(8): $3462-3469$

Shiah HS, Kuo YY, Tang JL, Huang SY, Yao M, Tsay W, Chen YC, Wang CH, Shen MC, Lin DT, Lin KH, Tien HF (2002) Clinical and biological implications of partial tandem duplication of the MLL gene in acute myeloid leukemia without chromosomal abnormalities at $11 \mathrm{q} 23$. Leukemia 16(2): 196-202

Shih LY, Huang CF, Wu JH, Lin TL, Dunn P, Wang PN, Kuo MC, Lai CL, Hsu HC (2002) Internal tandem duplication of FLT3 in relapsed acute myeloid leukemia: a comparative analysis of bone marrow samples from 108 adult patients at diagnosis and relapse. Blood 100(7): 2387-2392

Shih LY, Huang CF, Wu JH, Wang PN, Lin TL, Dunn P, Chou MC, Kuo MC, Tang CC (2004) Heterogeneous patterns of FLT3 Asp(835) mutations in relapsed de novo acute myeloid leukemia: a comparative analysis of 120 paired diagnostic and relapse bone marrow samples. Clin Cancer Res 10(4): $1326-1332$

Suzuki H, Watkins DN, Jair KW, Schuebel KE, Markowitz SD, Chen WD, Pretlow TP, Yang B, Akiyama Y, Van Engeland M, Toyota M, Tokino T, Hinoda Y, Imai K, Herman JG, Baylin SB (2004) Epigenetic inactivation of SFRP genes allows constitutive WNT signaling in colorectal cancer. Nat Genet 36(4): 417-422

Suzuki R, Onizuka M, Kojima M, Shimada M, Fukagawa S, Tsuboi K, Kobayashi H, Shintani A, Ogawa Y, Kawada H, Hotta T, Ando K (2007) Preferential hypermethylation of the Dickkopf-1 promoter in corebinding factor leukaemia. $\mathrm{Br} J$ Haematol 138(5): 624-631

Tang JL, Hou HA, Chen CY, Liu CY, Chou WC, Tseng MH, Huang CF, Lee FY, Liu MC, Yao M, Huang SY, Ko BS, Hsu SC, Wu SJ, Tsay W, Chen YC, Lin LI, Tien HF (2009) AML1/RUNX1 mutations in 470 adult patients with de novo acute myeloid leukemia: prognostic implication and interaction with other gene alterations. Blood 114(26): 5352-5361

Tien HF, Tang JH, Tsay W, Liu MC, Lee FY, Wang CH, Chen YC, Shen MC (2001) Methylation of the p15(INK4B) gene in myelodysplastic syndrome: it can be detected early at diagnosis or during disease progression and is highly associated with leukaemic transformation. $\mathrm{Br} \mathrm{J}$ Haematol 112(1): 148-154

Tien HF, Wang CH, Chuang SM, Chow JM, Lee FY, Liu MC, Chen YC, Shen MC, Lin DT, Lin KH (1994) Cytogenetic studies, ras mutation, and clinical characteristics in primary myelodysplastic syndrome. A study on 68 Chinese patients in Taiwan. Cancer Genet Cytogenet 74(1): 40-49

Tien HF, Wang CH, Lin MT, Lee FY, Liu MC, Chuang SM, Chen YC, Shen MC, Lin KH, Lin DT (1995) Correlation of cytogenetic results with immunophenotype, genotype, clinical features, and ras mutation in acute myeloid leukemia. A study of 235 Chinese patients in Taiwan. Cancer Genet Cytogenet 84(1): 60-68

Valencia A, Roman-Gomez J, Cervera J, Such E, Barragan E, Bolufer P, Moscardo F, Sanz GF, Sanz MA (2009) Wnt signaling pathway is epigenetically regulated by methylation of Wnt antagonists in acute myeloid leukemia. Leukemia 23(9): 1658-1666

Wang Y, Krivtsov AV, Sinha AU, North TE, Goessling W, Feng Z, Zon LI, Armstrong SA (2010) The Wnt/beta-catenin pathway is required for the development of leukemia stem cells in AML. Science 327(5973): 16501653

Willert K, Brown JD, Danenberg E, Duncan AW, Weissman IL, Reya T, Yates III JR, Nusse R (2003) Wnt proteins are lipid-modified and can act as stem cell growth factors. Nature 423(6938): 448-452

Ysebaert L, Chicanne G, Demur C, De Toni F, Prade-Houdellier N, Ruidavets JB, Mansat-De Mas V, Rigal-Huguet F, Laurent G, Payrastre B, Manenti S, Racaud-Sultan C (2006) Expression of beta-catenin by acute myeloid leukemia cells predicts enhanced clonogenic capacities and poor prognosis. Leukemia 20(7): 1211-1216

This work is published under the standard license to publish agreement. After 12 months the work will become freely available and the license terms will switch to a Creative Commons Attribution-NonCommercial-Share Alike 3.0 Unported License. 